
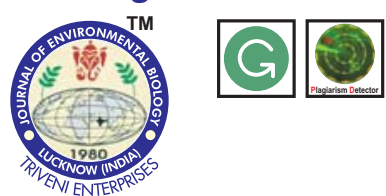

\title{
Efficacy of brassinosteroid analogues in the mitigation of toxic effects of salt stress in Brassica juncea plants
}

Authors Info

A.S. Wani', S. Hayat ${ }^{2 *}$, A. Ahmad ${ }^{2}$ and I. Tahir ${ }^{1}$

${ }^{1}$ Plant Physiology and Biochemistry Research Laboratary, Department of Botany, University of Kashmir, Srinagar-190006, India

${ }^{2}$ Plant Physiology Section, Department of Botany, Aligarh Muslim University, Aligarh-202 002, India

*Corresponding Author Email : hayat_68@yahoo.co.in

Key words

24-epibrassinolide, 28-homobrassinolide, Photosynthetic rate, Seed yield, Salt stress

Publication Info

Paper received : 03.11 .2015

Revised received: 19.03 .2016

Re-revised received : 24.05 .2016

Accepted: 14.07.2016
Abstract

Aim: Brassinosteroids have been recognized as sixth class of phytohormones which have the ability to confer tolerance against salinity stress. Brassinosteroids were applied through foliar spray on mustard plant under natural condition, as well as under stress.

Methodology: Analogues of Brassinosteroids (28-homobrassinolide, 24-epibrassinolide) were applied to the foliage of non-stressed and salinity stressed mustard plant under natural condition. Brassinosteroids neutralized the ill effect generated by $\mathrm{NaCl}$. Presence of $\mathrm{NaCl}$ in soil significantly decreased most of parameters.

Results: The results showed that the presence of $\mathrm{NaCl}$ in soil significantly decreased most of the parameters in concentration dependent manner. Whereas, out of the two brassinosteroid analogues, 24epibrassinolide excelled over 28-homobrassinolide and neutralized the ill effects generated by $\mathrm{NaCl}$.

Interpretation: It can be inferred from the observations that brassinosteroids (in particular 24epibrassinolide) can be used as an effective tool in the amelioration of salt stress.

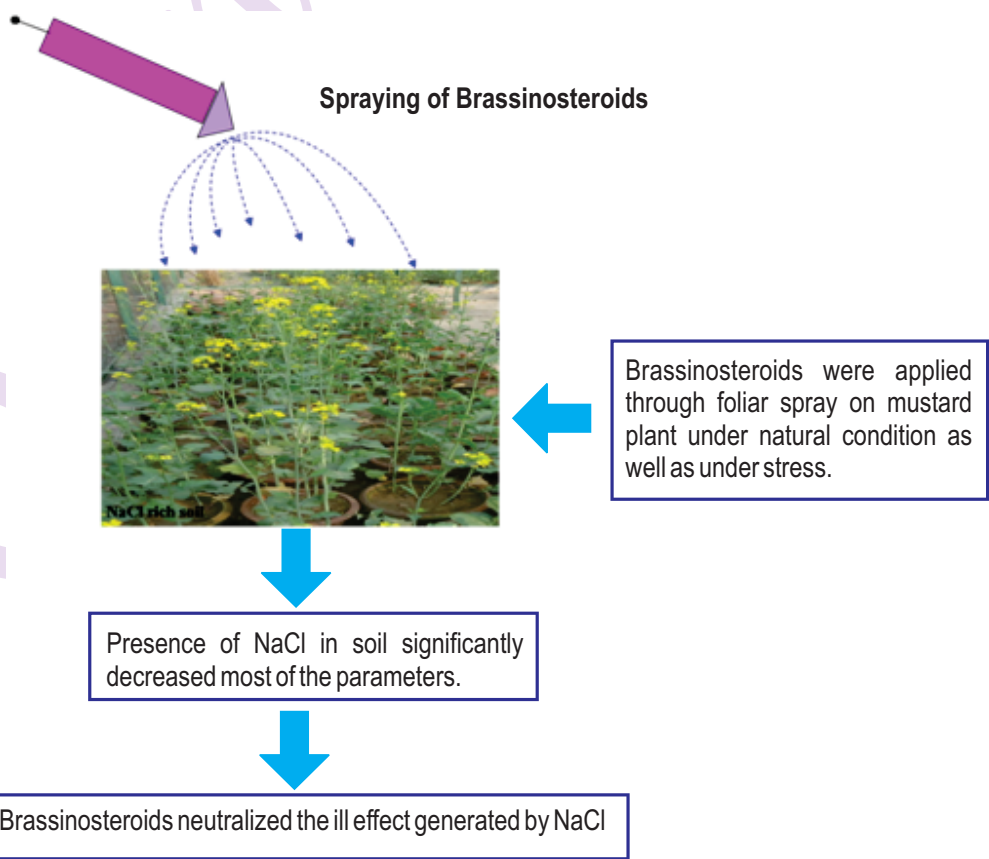




\section{Introduction}

India is the second largest producer of Brassicas supplying nearly $27.8 \%$ of world's total edible oil (Shekhawat et al., 2012). However, this supply still remains insufficient to fulfill the daily needs of the people (Shekhawat et al., 2012). This scarce production of Brassicas has been attributed to various biotic and abiotic stresses in the environment, among which salt stress has appeared as one of the serious threat to crop productivity (Hasanuzzaman et al., 2013). Uptake of essential minerals $\left(\mathrm{K}^{+}, \mathrm{Ca}^{2+}\right.$ and $\left.\mathrm{Mn}^{2+}\right)$ is reduced by excess accumulation of $\mathrm{Na}^{+}$and $\mathrm{Cl}$ in cells under salt stress due to ionic imbalances, which naturally distorts the physiology of plants (Almodares et al., 2014). Salinity stress decreases the stomatal conductance, internal $\mathrm{CO}_{2}$ pressure and stomatal opening which affects gaseous exchange leading to inhibition of photosynthesis (Wani et al., 2013). This salinity stress induced loss in the photosynthetic rate is responsible for retarded plant growth and productivity at maturity (Yadav et al., 2011). Osmotic stress, the primary symptom, causes leaf senescence during the phase of ion toxicity due to accumulation of excessive salts in the transpiring leaves (Munns, 2002). These factors altogether cause adverse pleotropic effects that lead to loss of plant growth and yield, at harvest.

Brassinosteroids, a class of poly-hydroxysteroids, have been recognized as sixth class of phyto-hormones which have been associated with wide range of plant physiological and molecular responses in plants. They have the ability to induce cell elongation and cell division in stem, promote xylem differentiation and abscission (Coll et al., 2016). They also have the ability to confer tolerance against osmotic stress, temperature stress, salinity stress, and heavy metals like, cadmium, nickel, aluminum and copper in plants (Coll et al., 2016).

Keeping in view the roles assigned to Brassinosteroids and the ever increasing salt stress in soil, the present experiment was designed with an aim to counteract the changes in growth and photosynthetic parameters in salinized plants of Brassica juncea (L.) Czern \& Coss by inducing resistance, against the stress through Brassinosteroids application. Two varieties of Brassica juncea (L.) Czern \& Coss namley Varuna and RH-30 were selected in this study based on their high and low photosynthesizing capacity, respectively.

\section{Materials and Methods}

Hormone solution : The stock solutions of 28-homobrassinolide (homobrassinolide) or 24-epibrassinolide (epibrassinolide) were prepared by dissolving the required quantity of homobrassinolide or epibrassinolide in $5 \mathrm{ml}$ of ethanol, in $100 \mathrm{ml}$ volumetric flasks. 5 $\mathrm{ml}$ of surfactant "Tween-20" was added to it and final volume was made up to the mark by using double distilled water. The desired concentrations $\left(10^{-8} \mathrm{M}\right)$ of homobrassinolide or epibrassinolide were prepared by diluting the stock solution with double distilled water.

Plant material: Authentic and healthy seeds of Brassica juncea (L.) Czern \& Coss cv. Varuna and RH-30 were procured from National Seed Corporation Ltd., New Delhi, India. The seeds were surface-sterilized with $0.01 \%$ mercuric chloride solution followed by repeated washing with double distilled water in order to remove adhered mercuric chloride on the seed surface. The experiment was conducted with 60 earthen pots in such a way that each treatment had five replicates and within each pot three plants were maintained under simple randomized block design. Surface sterilized seeds of Brassica juncea (L.) Czern \& Coss cv. Varuna and $\mathrm{RH}-30$ were sown in earthen pots $(25 \times 25 \mathrm{~cm})$, filled with equal quantity of sandy loam soil mixed with farmyard manure (9:1) amended with different levels $\left(2.8,4.2\right.$ or $\left.5.6 \mathrm{dsm}^{-1}\right)$ of $\mathrm{NaCl}$. These pots were placed in a net house of Botany department, Aligarh Muslim University, Aligarh, India under natural environmental conditions. At 29 days after sowing (DAS), the foliage of plants was sprayed with double distilled water, homobrassinolide $\left(10^{-8} \mathrm{M}\right)$ or epibrassinolide $\left(10^{-8} \mathrm{M}\right)$. Each plant was sprinkled three times at an interval of $10 \mathrm{~min}$ on the same day. The nozzle of the sprayer was adjusted in such a way that it pumped out $1 \mathrm{ml}$ of double distilled water or homobrassinolide or epibrassinolide solution in one sprinkle. The plants were then sampled at 60 DAS to assess various morphological and physiological parameters and at 120 DAS to study the yield parameters.

Growth characteristics: On the day of sampling, the plants were removed along with soil and dipped in water to dislodge the adhering soil particles while ensuring the integrity of roots. The plants were blotted and the lengths of root and shoot were measured, followed by their subsequent weighing to record fresh mass. The root and shoot were then oven dried $\left(80^{\circ} \mathrm{C}\right.$ for $\left.72 \mathrm{hr}\right)$ and weighed to note their dry mass. Leaf area was ascertained by gravimetric method by tracing the outline of leaf on graph sheet and counting the squares covered by it on a graph paper.

Electrolyte leakage, leaf water potential and carbonic anhydrase activity: The electrolyte leakage, leaf water potential and carbonic anhydrase activity were determined as discussed in our previous study (Wani et al., 2013).

Soil-Plant analysis development (SPAD) chlorophyll value, photosynthetic attributes and maximum quantum yield of PSII: The SPAD chlorophyll value, photosynthetic attributes [net photosynthetic rate $\left(P_{N}\right)$, stomatal conductance $\left(g_{s}\right)$, internal $\mathrm{CO}_{2}$ concentration $\left(C_{i}\right)$, and transpiration rate $(E)$ ] and maximum quantum yield of $\mathrm{PS} \| \mathrm{I}(\mathrm{Fv} / \mathrm{Fm})$ in the intact leaves were assessed as described in our previous study (Wani et al., 2013).

Statistical analysis: Treatment means were compared by the analysis of variance using SPSS (SPSS, ver. 17, Chicago, United 

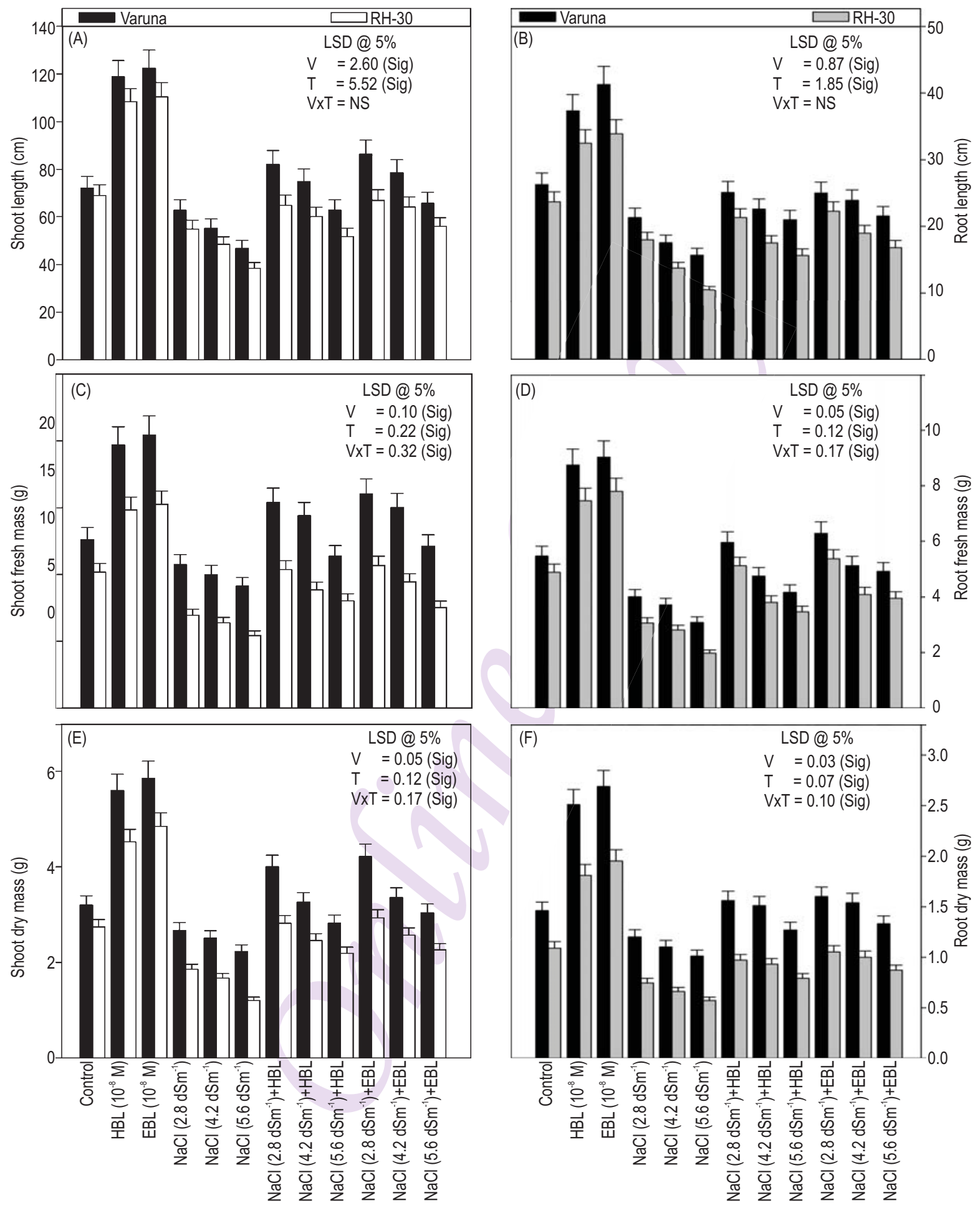

Fig. 1 : Effect of 28-homobrassinolide (HBL; $\left.10^{-8} \mathrm{M}\right)$ or 24-epibrassinolide (EBL; $\left.10^{-8} \mathrm{M}\right)$ as foliar spray (29 day stage) and/or soil applied sodium chloride $\left(\mathrm{NaCl} ; 2.8,4.2\right.$, or $\left.5.6 \mathrm{dsm}^{-1}\right)$ on (A) Shoot length, (B) Root length, (C) Shoot fresh mass, (D) Root fresh mass, (E) Shoot dry mass and (F) Root dry mass in two varieties (Varuna and RH-30) of Brassicajuncea (L.) Czern \& Coss at 60 DAS 
States). Least Significant Difference (LSD) was calculated at the $5 \%$ level of probability. Standard error between the replicates was also calculated.

\section{Results and Discussion}

The plants raised in soil amended with different levels $\left(2.8,4.2\right.$, or $\left.5.6 \mathrm{dsm}^{-1}\right)$ of $\mathrm{NaCl}$ exhibited a linear decrease in the values of all the growth characteristics (length, fresh mass and dry mass of root and shoot and leaf area) in both the varieties (Figs. 1,
$2 A)$. Varuna variety was more tolerant to stress than RH-30, attributed to its differential regulation of physiological, biochemical and genetical processes. The reason behind the salt induced decrease in plant growth is reduction of cell division and elongation (Pitann et al., 2009) which mainly occurs due to the alterations in the nutrient uptake, excess reactive oxygen species accumulation (Ashraf, 2009), cytoplasmic enzyme inhibition, turgor loss and hormonal imbalance (Iqbal and Ashraf, 2010) induced by the salt. The studies are further authenticated by the reports in sunflower (Akram and Ashraf, 2011) and Ocimum
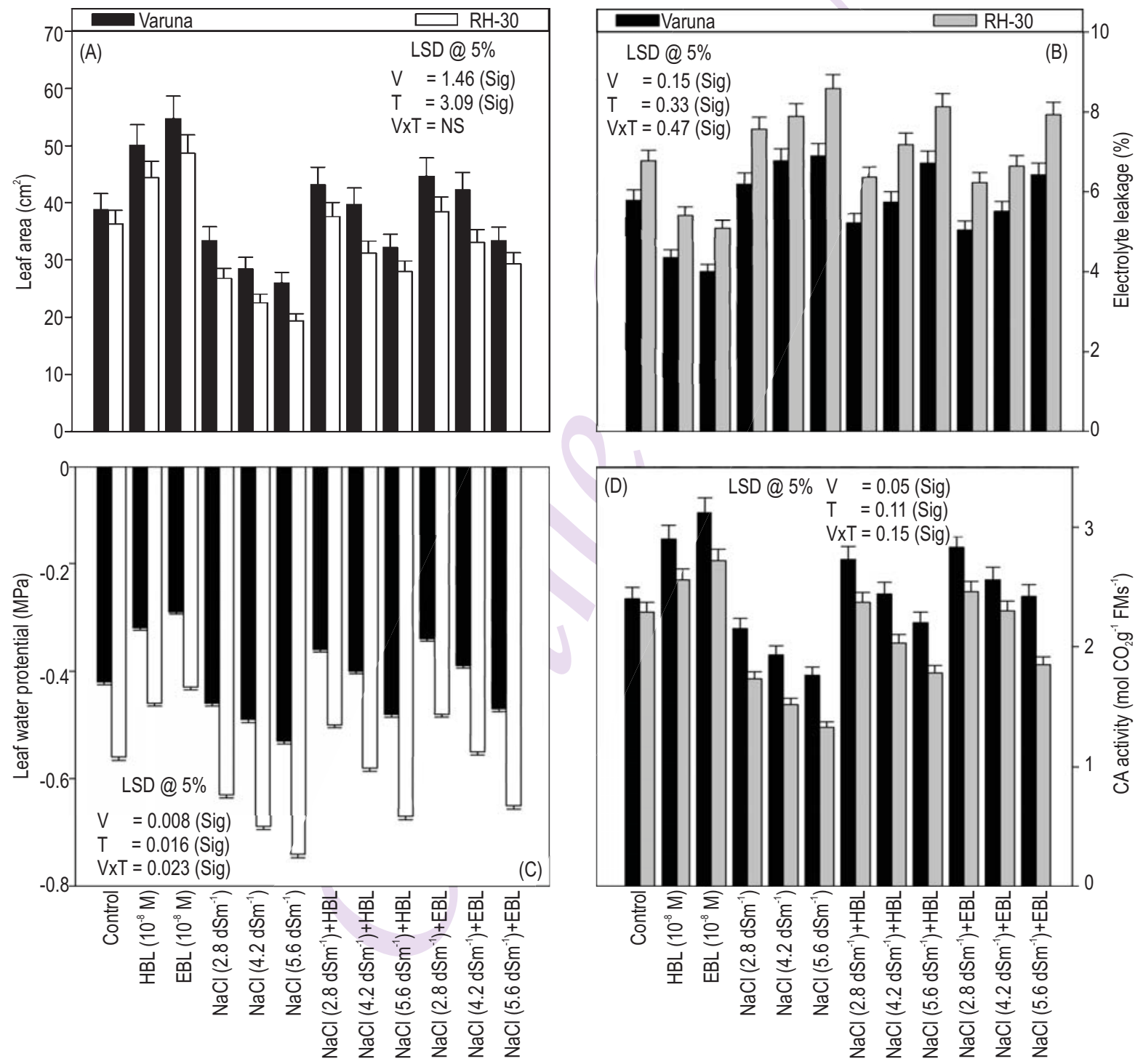

Fig. 2 : Effect of 28-homobrassinolide (HBL; $10^{-8} \mathrm{M}$ ) or 24-epibrassinolide (EBL; $10^{-8} \mathrm{M}$ ) as foliar spray (29 day stage) and/or soil applied sodium chloride $\left(\mathrm{NaCl} ; 2.8,4.2\right.$, or $\left.5.6 \mathrm{dsm}^{-1}\right)$ on (A) Leaf area, (B) Electrolyte leakage, (C) Leaf water potential and (D) Carbonic anhydrase (CA) activity in two varieties (Varuna and RH-30) of Brassicajuncea (L.) Czern \& Coss at60 DAS 
basilicum (Heidari, 2012) for similar responses. However, the foliage applied brassinosteroids (homobrassinolide/ epibrassinolide) of stressed or non-stressed plants improved plant growth. Out of these two, epibrassinolide was more effective in generating favorable response and increased the length of shoot and root by $70 \%$ and $57 \%$ in Varuna and $60 \%$ and $43 \%$ in $\mathrm{RH}-30$, over control plants (Fig. 1). Brassinosteroids are recognized to modulate a number of metabolic phenomena leading to plant resistance against the stress (Coll et al., 2016). Amelioration of salt stress by brassinosteroids application is well documented in various plants such as Cajanus cajan (Dalio et al., 2011), eggplant (Wu et al., 2012) etc. Brassinosteroids involves regulation of cell division and elongation (Peleg and Blumwald, 2011), genes encoding xyloglucan endo-transglyucosylase/ hydrolase i.e., enzymes responsible for the modification of cell wall activity and cell enlargement, cellulose synthase and sucrose synthase (Coll et al., 2016) that play a vital role in plant growth and development. Exogenous application of brassinosteroids accelerates plant growth and development, however, the extent of their effects may vary with plant species and their concentration applied. Moreover, reduction in the values of growth characteristics caused by lower concentrations ( 2.8 or $\left.4.2 \mathrm{dsm}^{1}\right)$ of $\mathrm{NaCl}$ was completely neutralized by brassinosteroids $\left(10^{-8} \mathrm{M}\right)$ spray in Varuna, where epibrassinolide was more effective than homobrassinolide. The foliage of Brassica plants exposed to brassinosteroids possessed larger leaves (Fig. 2A), which could be an expression of activated cell division and cellular enlargement (Bajguz and Tretyn, 2003). Similar observations have also been reported in Brassica juncea, under copper stress (Fariduddin et al., 2009) and in wheat under stress free conditions (Shahbaz et al., 2008).

Carbonic anhydrase enzyme is important in plant carbon acquisition. This enzyme catalyzes dehydration of $\mathrm{HCO}_{3}^{-}$and provides $\mathrm{CO}_{2}$ external to the plasma membrane of plant cells when $\mathrm{HCO}_{3}{ }^{-}$is available, but $\mathrm{CO}_{2}$ is limited (Badger, 2003). In the present study, $\mathrm{NaCl}$-induced stress caused a significant decrease in the activity of CA (Fig. 2D). It could be due the negative impact of salinity on gene expression of carbonic anhydrase (Liu et al., 2012). Under comparable conditions, Idrees et al. (2012) also reported loss of carbonic anhydrase activity. However, leaf applied brassinosteroids (homobrassinolide/epibrassinolide) to stressed or non-stressed plants increased the carbonic anhydrase activity. Epibrassinolide proved best and increased the activity by $30 \%$ and $18 \%$ in Varuna and $\mathrm{RH}-30$ respectively, over their control plants under stress-free conditions. This increase in the carbonic anhydrase activity is due to up-regulation of $\mathrm{CO}_{2}$ assimilation rate by brassinosteroids (Yu et al., 2004) that may be due to enhanced expression of genes that encode other enzymes of calvin cycle and also play an important role in regeneration of RUBP, thereby maximizing carboxylation rate of Rubisco (Xia et al., 2009), supported by Hayat et al. (2010) in tomato and Swamy and Rao (2009) in Pelargonium graveoleus.
The plants, under salt stress loss a significant level of leaf chlorophyll (Wani et al., 2013; Heidari, 2012), in a concentration and/or variety dependent manner (Fig. 3A). Presumably, salt stress either inhibits its synthesis or accelerates the degradation of chlorophyll molecules (Ashraf and Harris, 2013). However, this harmful effect of $\mathrm{NaCl}$ was completely overcome by brassinosteroids application to the foliage of plants of various crops (Hayat et al., 2011; Yu et al., 2004) because of their involvement in improving the related transcription and/or translation machinery (Bajguz and Asami, 2005) (Fig. 3A). Epibrassinolide established itself as the most effective brassinosteroids analogue in increasing SPAD chlorophyll by $30 \%$ in Varuna over control. Moreover, brassinosteroids also retard the rate of chlorophyll degradation and that of the proteins, in particular those associated with light-harvesting complexes in thylakoid membranes (Hola, 2011).

The stressed plants also exhibited a decrease in various photosynthetic attributes $\left(P_{N}, g_{s}, C_{i}\right.$ and $\left.E\right)$ in both the varieties (Fig. 3B-E). The highest concentration $\left(5.6 \mathrm{dsm}^{-1}\right)$ of $\mathrm{NaCl}$ decreased the values of $P_{N}, g_{s}, C_{i}$ and $E$ by $27 \%, 40 \%, 17 \%$, and $18 \%$ in Varuna and $46 \%, 52 \%, 32 \%$ and $29 \%$ in $\mathrm{RH}-30$ respectively, as compared with non-stressed control plants. $\mathrm{NaCl}$ induces stomatal closure due to decreased leaf turgor and atmospheric vapor pressure along with root-generated chemical signals (Chaves et al., 2009) which is the main cause for the observed loss of $g_{s}, C_{i}$ and $E$. This decrease in $g_{s}$ and $C_{i}$ directly results in the slow-down of net photosynthetic rate in stressed plants (Lu et al., 2009; Fig. 3B). Thus, decrease in the net photosynthetic rate under salt stress conditions is attributed to suppression in mesophyll conductance and stomata closure. Decrease in SPAD chlorophyll value (Fig. 3A) and carbonic anhydrase activity (Fig. 2D) may also be assigned as reasons for lowering $P_{N}$, in stressed plants. Wu et al (2012) reported that salt stress decreased the photosynthetic rate in eggplants, whereas, Hakim et al (2014) also noted that the decreased photosynthesis in rice plants under saline stress However, brassinosteroids (homobrassinolide/epibrassinolide) alone or as a follow-up treatment to the stressed plants improved all the photosynthetic attributes in both the varieties (Fig. 3B-E). The two important enzymes that initiate the process of photosynthesis i.e., carbonic anhydrase and Rubisco, are assigned to be initiated by brassinosteroids (Yu et al., 2004). The higher carbonic anhydrase activity increases the carboxylation state of Rubisco (Bajguz and Asami, 2005), thereby improves $P_{N}$ (Fig. 3B). It may, therefore be inferred that brassinosteroids improved the $\mathrm{CO}_{2}$ concentration (Fig. 3D) by increasing $g_{s}$ (Fig. $3 \mathrm{C}$ ) and also the efficiency of light harvesting system by elevating the level of chlorophyll (Fig. 3A) whose cumulative action speeded up the net photosynthetic rate of the plants (Hola, 2011; Fig. 3B). Moreover, brassinosteroids improved the water relations i.e. leaf water potential (Fig. 2C), membrane structure and its stability (Yan et al., 2011) also 

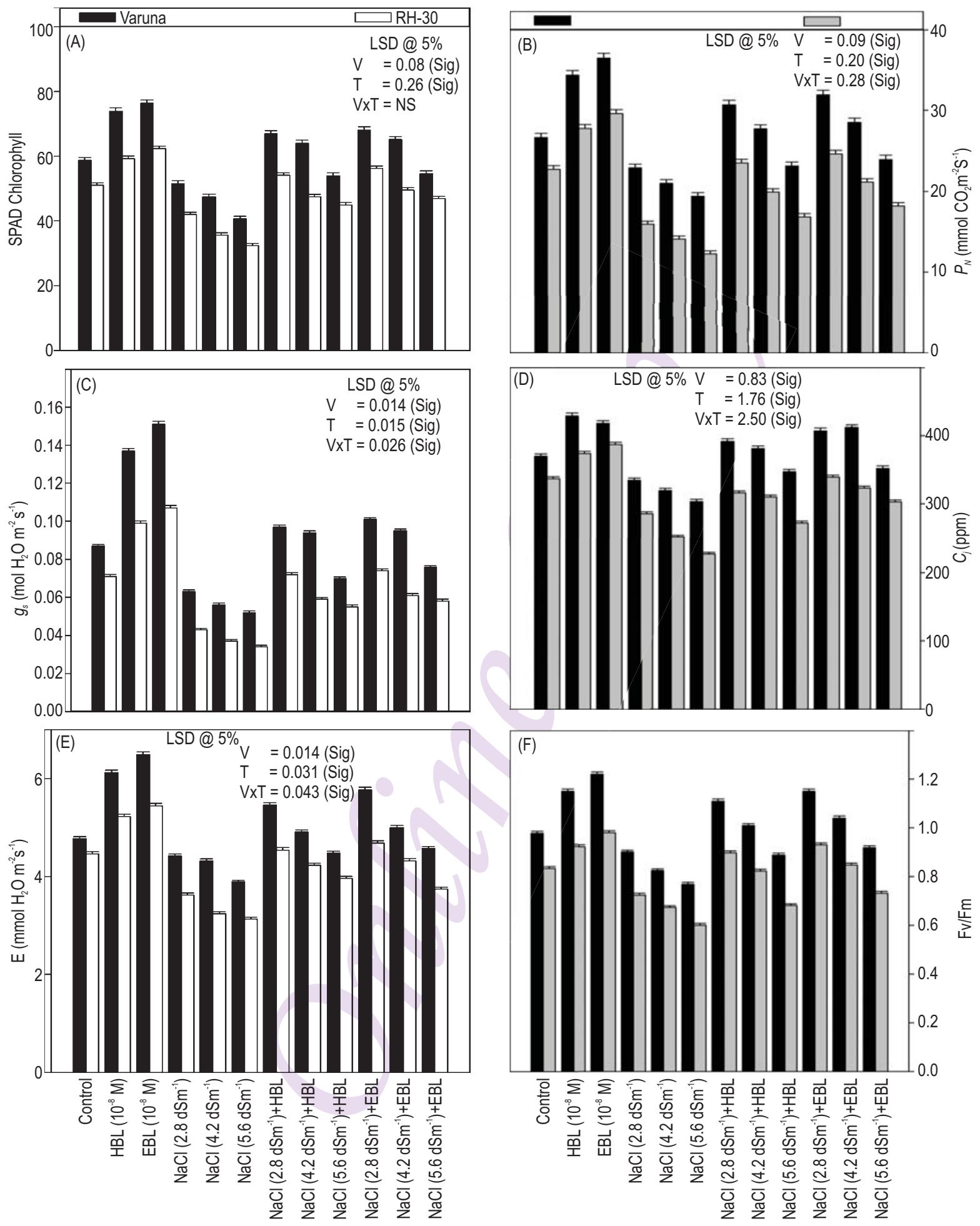

Fig. 3 : Effect of 28 -homobrassinolide $\left(\mathrm{HBL} ; 10^{-8} \mathrm{M}\right)$ or 24 -epibrassinolide $\left(\mathrm{EBL} ; 10^{-8} \mathrm{M}\right)$ as foliar spray (29 day stage) and/or soil applied sodium chloride $\left(\mathrm{NaCl} ; 2.8,4.2\right.$, or $5.6 \mathrm{dsm}^{-1}$ ) on (A) SPAD chlorophyll, (B) Net photosynthetic rate; $P_{N}$, (C) Stomatal conductance; $g_{s}$, (D) Internal $\mathrm{CO}_{2}$ concentration; $C_{i}$, (E) Transpiration rate; Eand (F) Maximum quantum yield of PSII; Fv/Fm in two varieties (Varuna and RH-30) of Brassica juncea (L.) Czern \& Coss at 60 DAS 

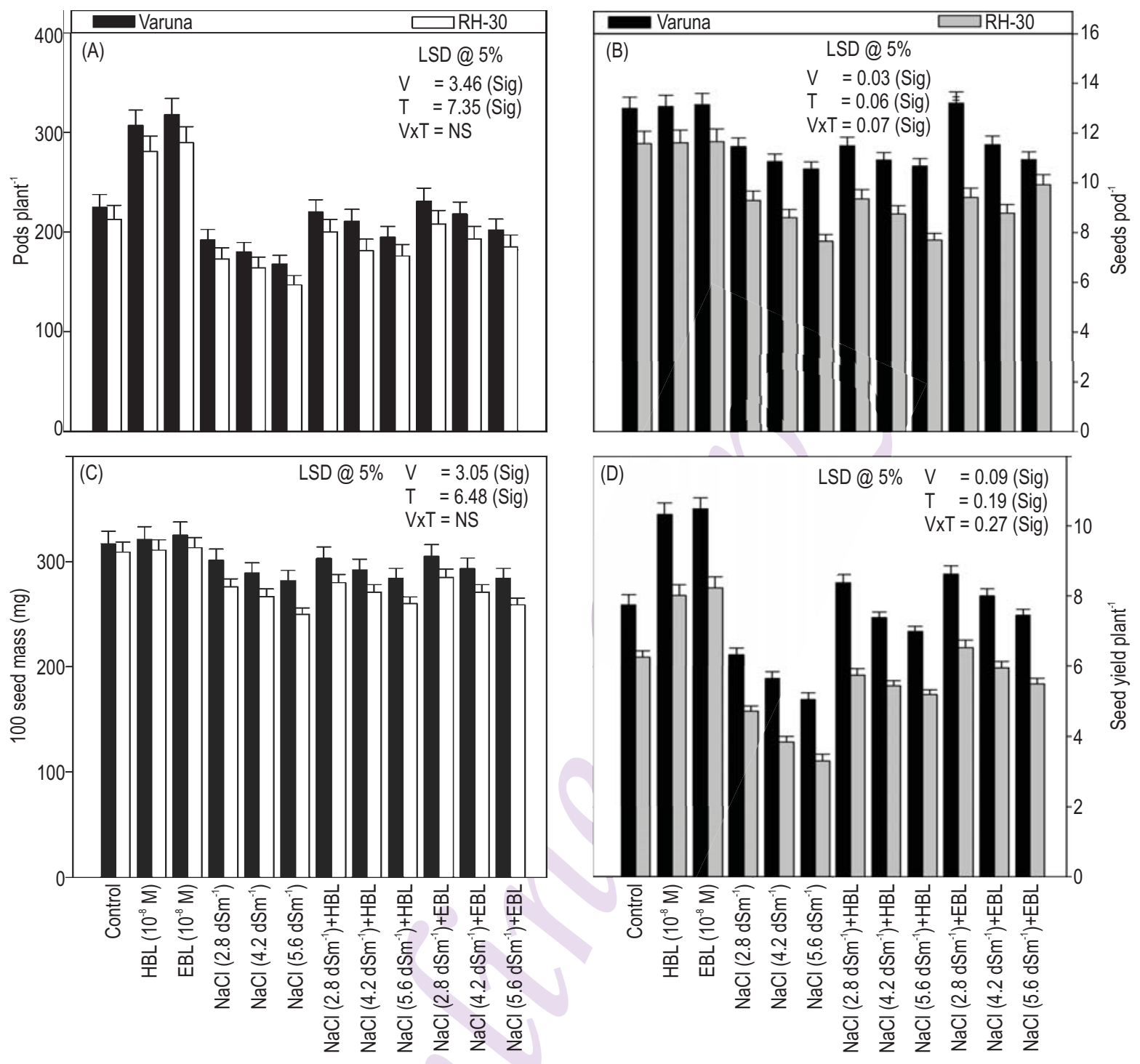

Fig. 4 : Effect of 28-homobrassinolide (HBL; $\left.10^{-8} \mathrm{M}\right)$ or 24 -epibrassinolide $\left(\mathrm{EBL} ; 10^{-8} \mathrm{M}\right)$ as foliar spray (29 d stage) and/or soil applied sodium chloride $\left(\mathrm{NaCl} ; 2.8,4.2\right.$, or $5.6 \mathrm{dsm}^{-1}$ ) on (A) Pods plant ${ }^{-1}$, (B) Seeds pod ${ }^{-1}$, (C) 100 seed mass and (D) Seed yield plant ${ }^{-1}$ in two varieties (Varuna and RH-30) of Brassicajuncea (L.) Czern \& Coss at 120 DAS

expressed by the decreased electrolyte leakage in the present study (Fig. 2B).

The plants exposed to salt stress had significantly lower values for quantum yield of PSII (Fig. 3F) because of the damage in PSII electron transport system (Megdiche et al., 2008). The highest concentration of salt $\left(5.6 \mathrm{dsm}^{-1}\right)$ decreased Fv/Fm values by $21 \%$ and $28 \%$ in Varuna and $\mathrm{RH}-30$ respectively, when compared with control plants. $\mathrm{NaCl}$ decreases the photochemical efficiency leading to suppression of PSII activity (Mehta et al., 2010). It also blocks the electron transfer from primary acceptor, plastoquinone $(\mathrm{QA})$ to the secondary acceptor plastoquinone (QB) at the acceptor side of PSII which leads to decrease in $\mathrm{Fv} / \mathrm{Fm}$ values (Shu et al., 2012). Similar observations have also been reported in other crops, Solanum melongena (Wu et al., 2012) and Cucumis sativus (Shu et al., 2012) on being exposed to salt stress. However, the brassinosteroids applied to foliage of Brassica improved the values of $\mathrm{Fv} / \mathrm{Fm}$ both in the presence or absence of $\mathrm{NaCl}$ stress (Fig. 3F). Out of two Brassinosteroids analogues epibrassinolide proved best and completely neutralized the damage caused by two lower concentrations of $\mathrm{NaCl}\left(2.8\right.$ or $\left.4.2 \mathrm{dsm}^{-1}\right)$ in Varuna. Brassinosteroids protect PSII 
against over-excitation, under salt stress that otherwise could have caused the loss of integrity of thylakoid membrane (Wu et al., 2012). Brassinosteroids induced protection of Fv/Fm, under salt stress, is also reported earlier in Solanum melongena (Wu et al., 2012) and wheat (Shahbaz et al., 2008).

The yield characteristics (number of pods per plant, number of seeds per pod, 100 seed mass and seed yield per plant) decreased significantly with the increase in $\mathrm{NaCl}$ level in soil (Fig. 4). The highest $\mathrm{NaCl}$ level $\left(5.6 \mathrm{dsm}^{-1}\right)$ generated maximum damage to number of pods per plant $(25 \%, 31 \%)$, number of seeds per pod (18\%, 34\%), 100 seed mass (11\%, 19\%) and seed yield per plant $(35 \%, 47 \%)$, in Varuna and $\mathrm{RH}-30$, respectively, as compared with non-stressed plants. Loss in the seed yield, under salt stress can be attributed to the observed poor plant growth (Fig. 1) resulting largely from the lower pace of photosynthesis (Fig. 3B, Chen et al., 2009). These results are in confirmity with those of Asgari et al. (2012) who noted that salt stress decreased the growth and leaf ion conc. corresponds to decreased yield under salt stress in wheat plant. Later Wani et al. (2013) also reported the decreased seed yield in the presence of $\mathrm{NaCl}$ in mustard plant. Under salt stress, the thickness of assimilate conducting pathway gets reduced (Aldesuquy and Ibrahim, 2001), and the leaves start behaving as sink rather than source (Arbona et al., 2005). This causes inhibition of assimilate movement towards the developing reproductive organs, which might be the reason for the observed decrease in the yield characteristics. However, stress-free and stressed plants, applied with brassinosteroids to their foliage, exhibited an improvement in the values for yield characteristics, at harvest (Fig. 4). The possible reason for increase in the crop yield might be due to BRinduced action on senescence of plant organs (leaves and flowers) (Iwahori et al., 1990) that will automatically increase the life span of photosynthetically active sites. This consequently resulted in the observed increase in the number of pods per plant and ultimately increased seed yield per plant (Fig. 4). The observed increase in photosynthetic $\mathrm{CO}_{2}$ assimilation rate i.e., $P_{N}$, under brassinosteroids (Fig. 3B) will naturally result in the availability of more carbohydrates for metabolism and export to the sink (Bajguz and Asami, 2005). Therefore, availability of additional photosynthates at the sink in association with induced expression of genes encoding enzymes for carbohydrate metabolism (Roitsch, 1999) lead to the improved seed yield (Fig 4D). Similarly, higher biological yield in passion fruit, correlating with higher photosynthetic $\mathrm{CO}_{2}$ assimilation, under brassinosteroids (Gomes et al., 2003) was reported. Brassinosteroids favored improvement in the yield characteristics in Cicer arientinum exposed to cadmium stress (Hasan et al., 2008) has also been reported earlier.

Out of the two analogues of brassinosteroids (homobrassinolide/ epibrassinolide) used in the study, epibrassinolide proved more effective in improving the values of most of the parameters studied both in stress-free and stressed plants possibly due to differences in the structure and stability (Khripach et al., 2003). In almost all brassinosteroids, S-oriented alkyl (methyl or ethyl) group at C-24 of side chain is present while epibrassinolide and CS (another brassinosteroids analogue) being exceptions, have R-oriented alkyl group on the side chain of the steroid nucleus. The attachment of epibrassinolide to its plasma membrane receptor leads to more distorted three dimensional conformational states as compared to homobrassinolide. This thermodynamically acquired new stable state of epibrassinolide seems to be more actively involved in triggering wide array of favorable signal cascades than homobrassinolide. However, more research is required to know about the transcription factors that are involved in BRI-1 kinase inhibitor-1 (BKI-1) dissociation with BRI-1 associated kinase 1 (BAK-1) to avail the binding in brassinosteroid insensitive-1 (BRI-1) at membrane (Hategan et al., 2011; Codreanu and Russinova, 2011).

It can be concluded from the present study that brassinosteroids can be used as stress alleviators of $\mathrm{NaCl}$. Brassinosteroids (especially epibrassinolide) may, therefore, be applied to the plant foliage to improve the biological yield, and to ameliorate the toxic effects of stress in Brassicajuncea.

\section{Acknowledgment}

Dr. Arif Shafi Wani thank SERB, DST, New Delhi, India for providing fellowship under Young Scientist (SB/YS/LS-389/2013) scheme.

\section{References}

Akram, N.A. and M. Ashraf: Pattern of accumulation of inorganic elements in sunflower (Helianthus annuus L.) plants subjected to salt stress and exogenous application of 5-aminolevulinic acid. Pak. J. Bot., 43, 521-530 (2011).

Aldesuquy, H.S. and A.H. Ibrahim: Interactive effect of seawater and growth bio-regulators on water relations, absicisic acid concentration, and yield of wheat plants. J. Agron. Crop Sci., 187, 185-193 (2001).

Almodares, A., M.R. Hadi, B. Kholdebarin, B. Samedani and Z.A. Kharazian: The response of sweet sorghum cultivars to salt stress and accumulation of $\mathrm{Na}^{+}, \mathrm{Cl}^{-}$and $\mathrm{K}^{+}$ions in relation to salinity. $\mathrm{J}$. Environ. Biol., 35, 733-739 (2014).

Arbona, V., A.J. Marco, D.J. ljlesias, M.F. Lopez-Climent, M. Talon and A. Gómez-Coudenas: Carbohydrate depletion in roots and leavers of salt stressed potted Citrus clemtina L. Plant Growth Reg., 46, 153160 (2005).

Asgari, H.R., W. Cornelis and P. Van Damme: Salt stress effect on wheat (Triticum aestivum L.) growth and leaf ion concentrations. Intl. J. Plant Prod., 6, 195-208 (2012).

Ashraf, M. and P.J.C. Harris: Photosynthesis under stressful environments: An overview. Photosynthetica, 51, 163-190 (2013).

Ashraf, M.: Biotechnological approach of improving plant salt tolerance using antioxidants as markers. Biotech. Adv., 27, 84-93 (2009).

Badger, M.: The roles of carbonic anhydrases in photosynthetic $\mathrm{CO}_{2}$ concentrating mechanisms. Photosynthesis Res., 77, 83-94 (2003). 
Bajguz, A. and A. Tretyn: The chemical characteristic and distribution of brassinosteroids in plants. Phytochem., 62, 1027-1046 (2003).

Bajguz, A. and T. Asami: Suppression of Wolfûa arrhiza growth by brassinazole, an inhibitor of brassinosteroid biosynthesis and its restoration by endogenous 24-epibrassinolide. Phytochem., 66, 1787-1796 (2005).

Chaves, M.M., J. Flexas and C. Pinheiro: Photosynthesis under drought and salt stress: regulation mechanisms from whole plant to cell. Ann. Bot., 103, 551-560 (2009).

Chen, C., D. Huang and J. Liu: Functions and toxicity of nickel in plants: Recent advances and future prospects. Clean-Soil, Air, Water, 37, 304-313 (2009).

Codreanu, M.C. and E. Russinova: Regulatory mechanism of brassinosteroid signaling in plants. In: Brassinosteroids: A class of plant hormone (Eds.: S. Hayat and A. Ahmad) Springer, New York. pp. 29-56 (2011).

Coll, Y., F. Coll, A. Amorós and M. Pujol: Brassinosteroids roles and applications: an up-date. Biologia. 70, 726-732 (2016).

Dalio, R.J.D., H.P. Pinheiro, L. Sodek and C.R.B. Haddad: The effect of 24-epibrassinolide and clotrimazole on the adaptation of Cajanus cajan (L.) Mill sp. to salinity. Acta Physiol. Plant., 33, 1887-1896 (2011).

Fariduddin, Q., S. Khanam, S.A. Hasan, B. Ali, S. Hayat and A. Ahmad: Effect of 28-homobrassinolide on drought stress induced changes in photosynthesis and antioxidant system of Brassica juncea $\mathrm{L}$. Acta Physiol. Plant., 31, 889-897 (2009).

Gomes, M.M.A., T.M. Ferraz, A.T. Netto, R.C.C. Rosa, E. Campostrini, N.R. Leal, M.A.T. Zullo and M. Nunez-Vazquez: Effects of brassinosteroids on gas exchange and chlorophyll fluorescence in yellow passion fruit subjected to water stress. Braz. J. Plant Physiol., 15, 348 (2003).

Hakim, M.A., A.S. Juraimi, M.M. Hanafi, E. Ali, M.R. Ismail, A. Selamat and S.M.R. Karim: Effect of salt stress on morpho-physiology, vegetative growth and yield of rice. J. Environ. Biol., 35, 317-326 (2014).

Hasan, S.A., S. Hayat, B. Ali and A. Ahmad: 28-homobrassinolide protects chickpea (Cicer arietinum) from cadmium toxicity by stimulating antioxidant. Environ. Poll., 151, 60-66 (2008).

Hasanuzzaman, M., K. Nahar and M. Fujita: Plant response to salt stress and role of exogenous protectants to mitigate salt-induced damages. In: Ecophysiology and responses of plants under salt stress (Eds.: P. Ahmad, M.M. Azooz and M.N.V. Prasad) Springer, New York. pp. 25-87 (2013).

Hategan, L., B. Godza and M. Szekeres: Regulation of brassinosteroid metabolism. In: Brassinosteroids: A class of plant hormone (Eds.: S. Hayat and A. Ahmad) Springer, New York. pp. 57-81 (2011).

Hayat, S., S. Yadav, A.S. Wani, M. Irfan and A. Ahmad: Comparative effect of 28-homobrassinolide and 24-epibrassinolide on the growth, carbonic anhydrase activity and photosynthetic efficiency of Lycopersicon esculentum. Photosynthetica, 49, 397-404 (2011).

Hayat, S., S. Yadav, B. Ali and A. Ahmad: Interactive effect of nitric oxide and brassinosteroids on photosynthesis and the antioxidant system of tomato (Lycopersicon esculentum). Russ. J. Plant Physiol., 57, 224-133 (2010).

Heidari, M.: Effects of salinity stress on growth, chlorophyll content and osmotic components of two basil (Ocimum basilicum L.) genotypes. African J. Biotech., 11, 379-384 (2012)

Hola, A.: Brassinosteroids and photosynthesis. In: Brassinosteroids: A class of plant hormone (Eds.: S. Hayat and A. Ahmad) Springer, New York. pp. 143-192 (2011).

Idrees, M., M. Naeem, M.N. Khan, T. Aftab, M.M.A. Khan, Moinuddin: Alleviation of salt stress in lemongrass by salicylic acid. Protoplasma, 249, 709-720 (2012).

Iqbal, M. and M. Ashraf: Gibberellic acid mediated induction of salt tolerance in wheat plants: growth, ionic partitioning, photosynthesis, yield and hormonal homeostasis. Environ. Exp. Bot., 86, 76-85 (2010).

Iwahori, S., A. GarcõÂa-Luis, P. Santamarina, C. Monerri and J.L. Guardiola: The influence of ringing on bud development and flowering in Satsuma mandarin. J. Exp. Bot., 41, 1341-1346 (1990).

Khripach, V.A., V.N. Zhabinskii and N.B. Khripach: New practical aspects of brassinosteroids and results of their 10 year agricultural use in Russia and Balarus. In: Brassinosteroids: Bioactivity and crop productivity (Eds.: S. Hayat and A. Ahmad). Kluwer Academic Publishers, Dordrecht, Netherland, pp. 189-230 (2003).

Liu, W., Y. Ming, P. Li and Z. Huang: Inhibitory effects of hypo-osmotic stress on extracellular carbonic anhydrase and photosynthetic efûciency of green alga Dunaliella salina possibly through reactive oxygen species formation. Plant Physiol. Biochem., 54, 43-48 (2012).

Lu, K.X., B.H. Cao, X.P. Feng, Y. He and D.A. Jiang: Photosynthetic response of salt tolerant and sensitive soybean varieties. Photosynthetica, 47, 381-387 (2009).

Megdiche, W., K. Hessini, F. Gharbi, C.A. Jaleel, R. Ksouri and C. Abdelly: Photosynthesis and photosystem-2 efûciency of two saltadapted halophytic seashore Cakile maritima ecotypes. Photosynthetica, 46, 410-419 (2008).

Mehta, P., A. Jajoo, S. Mathur and S. Bharti: Chlorophyll-a florescence study revealing effects of high salt stress on Photosystem II in wheat leaves. Plant Physiol. Biochem., 48, 16-20 (2010).

Munns, R.: Comparative physiology of salt and water stress. Plant Cell Environ., 25, 239-250 (2002)

Peleg, Z. and E. Blumwald: Hormone balance and abiotic stress tolerance in crop plants. Curr. Opn. Plant Biol., 14, 290-295 (2011).

Pitann, B., S. Schubert and K.H. Mühling: Decline in leaf growth under salt stress is due to an inhibition of $\mathrm{H}^{+}$pumping activity and increase in apoplastic pH of maize leaves. J. Plant Nutr. Soil Sci., 172, 535-543 (2009).

Roitsch, T.: Source-sink regulation by sugars and stress. Curr. Opn. Plant Biol., 2, 198-206 (1999).

Shahbaz, M., M. Ashraf and H.R. Athar: Does exogenous application of 24-epibrassinolide ameliorate salt induced growth inhibition in wheat (Triticum aestivum L.)? Plant Growth Reg., 55, 51-64 (2008).

Shekhawat, K., S.S. Rathore, O.P. Premi, B.K. Kandpal and J.S. Chauhan: Advances in agronomic management of Indian mustard (Brassica juncea (L.) Czernj. Cosson): An overview. Intl. J. Agron., 2012, 1-14 (2012).

Shu, S., S.R. Guo, J. Sun and L.Y. Yuan: Effects of salt stress on the structure and function of the photosynthetic apparatus in Cucumis sativus and its protection by exogenous putrescine. Physiol. Plant., 146, 285-296 (2012).

Swamy, K.N. and S.S.R. Rao: Effect of 24-epibrassinolide on growth, photosynthesis and essential oil content of Pelargonium graveolens L. Herit. Russ. J. Plant Physiol., 56, 682-687 (2009).

Wani, A.S., A. Ahmad, S. Hayat and Q. Fariduddin: Salt-induced 
modulation in growth, photosynthesis and antioxidant system in two varieties of Brassica juncea. Saudi J. Biol. Sci., 20, 183-193 (2013).

Wu, X.X., H.D. Ding, Z.W. Zhu, S.J. Yang and D.S. Zha: Effects of 24epibrassinolide on photosynthesis of eggplant (Solanum melongena L.) seedlings under salt stress. African J. Biotech., 11, 8665-8671 (2012).

Xia, X.J., L.F. Huang, Y.H. Zhou, W.H. Mao, K. Shi, J.X. Wu, T. Asami, Z. Chen and J.Q. Yu: Brassinosteroids promote photosynthesis and growth by enhancing activation of Rubisco and expression of photosynthetic genes in Cucumis sativus. Planta, 230, 1185-1196 (2009).
Yan, Z., S. Guo, S. Shu, J. Sun and T. Tezuka: Effects of proline on photosynthesis, root reactive oxygen species (ROS) metabolism in two melon cultivars (Cucumis melo L.) under $\mathrm{NaCl}$ stress. African J. Biotech., 10, 18381-18390 (2011).

Yadav, S., M. Irfan, A. Ahmad and S. Hayat: Causes of salinity and plant manifestations to salt stress: A review. J. Environ. Biol., 32, 667685(2011).

Yu, J.Q., L.F. Huang, W.H. Hu, Y.H. Zhou, W.H. Mao, S.F. Ye and S. Nogues: A role of brassinosteroids in the regulation of photosynthesis in Cucumis sativus. J. Exp. Bot., 55, 1135-1143 (2004). 